See Article page XXX.

\section{Commentary: The importance of achieving leaflet coaptation in mitral repair for functional mitral regurgitation: It's just math!}

\author{
Alexander A. Brescia, MD, MSc, and \\ Steven F. Bolling, MD, on behalf of the Michigan \\ Mitral Research Group
}

Misumi and colleagues ${ }^{1}$ performed an interesting analysis of left ventricular end systolic dimension (LVESD) to annuloplasty ring size ratio to determine whether LVESD to ring size mismatch is associated with recurrent mitral regurgitation (MR). In a sample of 66 patients undergoing restrictive mitral annuloplasty between 2003 and 2014, the authors found that recurrent MR was more common in the group with an LVESD to ring size ratio $>2.42$ (17 out of 30 $[56 \%]$ ) compared with a ratio $\leq 2.42$ (6 out of $36[17 \%$; $P<.01)$.

As described, the importance of mismatch between LV and mitral valve (MV) ring size has been demonstrated in ischemic MR, ${ }^{2}$ but not for nonischemic MR. This analysis offers quantitative guidance for avoiding too much undersizing when performing a restrictive annuloplasty in patients with functional mitral regurgitation (FMR). As expected, postoperative LV dimensions were significantly reduced in both mismatch and nonmismatch patients. ${ }^{1}$ However, only LVESD to ring size ratio was found to be significantly associated with recurrent MR in a multivariable analysis, with a wide confidence interval due to the small sample size (odds ratio, 4.65; 95\% confidence interval, 1.04-25.0; $P=.048$ ) spanning parts of 12 years. ${ }^{1}$ This analysis is hypothesis-generating and illustrates important concepts for MV repair for FMR.

\footnotetext{
From the Department of Cardiac Surgery, University of Michigan, Ann Arbor, Mich. Disclosures: The authors reported no conflicts of interest.

The Journal policy requires editors and reviewers to disclose conflicts of interest and to decline handling or reviewing manuscripts for which they may have a conflict of interest. The editors and reviewers of this article have no conflicts of interest.

Received for publication July 5, 2021; revisions received July 5, 2021; accepted for publication July 7, 2021.

Address for reprints: Alexander A. Brescia, MD, MSc, Department of Cardiac Surgery, Frankel Cardiovascular Center, University of Michigan, 1500 E Medical Center Dr, Ann Arbor, MI 48109 (E-mail: abrescia@med.umich.edu).

J Thorac Cardiovasc Surg 2021; $\mathbf{\square}: 1-2$

$0022-5223 / \$ 36.00$

Copyright (C) 2021 by The American Association for Thoracic Surgery

https://doi.org/10.1016/j.jtcvs.2021.07.005
}

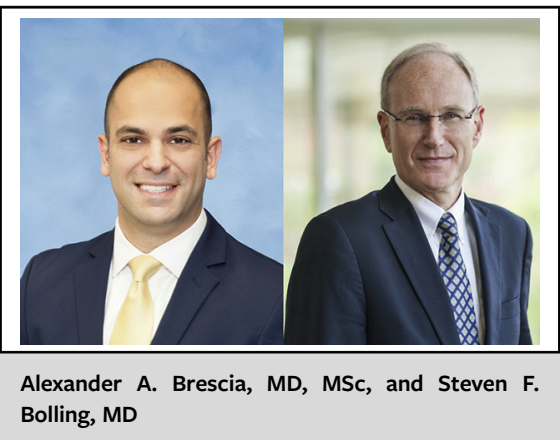

CENTRAL MESSAGE

Performing restrictive annuloplasty in the setting of a large left ventricle may result in mismatch. The risk of recurrent MR is increased when a zone of coaptation 8- to 10-mm long cannot be achieved.

An important principle in all MV surgery is avoidance of residual and recurrent $\mathrm{MR} .{ }^{3}$ We have previously described and reported outcomes of using a restrictive annuloplasty for FMR..$^{4-9}$ We routinely implant an undersized complete annuloplasty ring in patients with FMR, achieved by sizing the anterior leaflet. The present study illustrates the concept that an undersized ring in an extremely large LV may force the posterior leaflet to tip forward, but not augment the zone of leaflet coaptation and therefore result in recurrent MR. This may partially explain the poor results for mitral repair in the Cardiothoracic Surgical Trials Network trial for ischemic MR, in which many patients had very large ventricles, the achieved zone of coaptation was not measured, and the rate of recurrent MR at 2 years in the repair group was $59 \% .{ }^{10}$

In our practice, we aim for a zone of coaptation approximately 8 - to $10-\mathrm{mm}$ long. To achieve this, we use a $26-\mathrm{mm}$ or 28-mm full ring annuloplasty on nearly every patient with FMR requiring repair. The shape of the MV is an ellipse, with both anterior-posterior (A-P) and commissurecommissure diameters. We have found that for every $2 \mathrm{~mm}$ in A-P diameter reduction, the zone of coaptation lengthens by approximately $1 \mathrm{~mm}$. Accordingly, ring size may not be the best metric to characterize mismatch because even same-sized rings will differ in shape and A-P diameter.

We congratulate the authors for this novel contribution. Some FMR ventricles may be too large to repair. In this 
context, mismatch between restrictive annuloplasty and ventricular size may result in tipping of the posterior leaflet, inadequate leaflet coaptation, and recurrent MR. Patients with FMR need other strategies: replacement, cardiac resynchronization therapy, a clip, or LV assist device, for example. However, the best metric for successful FMR repair is the length of zone of coaptation that is achieved: It's just math!

\section{References}

1. Misumi Y, Kainuma S, Toda K, Miyagawa S, Yoshioka D, Hirayama A, et al. Left ventricular to mitral valve ring size mismatch following ring annuloplasty for nonischemic dilated cardiomyopathy. J Thorac Cardiovasc Surg. 2021. XXX:XXX.

2. Capoulade R, Zeng X, Overbey JR, Ailawadi G, Alexander JH, Ascheim D, et al. Impact of left ventricular to mitral valve ring mismatch on recurrent ischemic mitral regurgitation after ring annuloplasty. Circulation. 2016;134:1247-56.
3. Brescia AA, Bolling SF, Michigan Mitral Research Group. Commentary: MR is bad! J Thorac Cardiovasc Surg. May 31, 2020 [Epub ahead of print].

4. Bolling SF, Deeb GM, Brunsting LA, Bach DS. Early outcome of mitral valve reconstruction in patients with end-stage cardiomyopathy. J Thorac Cardiovasc Surg. 1995;109:676-82.

5. Bolling SF, Bach DS. Improvement following correction of secondary mitral regurgitation in end-stage cardiomyopathy with mitral annuloplasty. Am J Cardiol. 1996;78:966-9.

6. Bolling SF, Pagani FD, Deeb GM, Bach DS. Intermediate-term outcome of mitral reconstruction in cardiomyopathy. J Thorac Cardiovasc Surg. 1998;115:381-6.

7. Smolens IA, Bolling SF. Surgical approaches to dilated cardiomyopathy. Curr Cardiol Rep. 2000;2:99-105.

8. Smolens IA, Pagani FD, Bolling SF. Mitral valve repair in heart failure. Eur J Heart Fail. 2000;2:365-71.

9. Romano MA, Bolling SF. Update on mitral repair in dilated cardiomyopathy. $J$ Card Surg. 2004;19:396-400.

10. Goldstein D, Moskowitz AJ, Gelijns AC, Ailawadi G, Parides MK, Perrault LP, et al. Two-year outcomes of surgical treatment of severe ischemic mitral regurgitation. N Engl J Med. 2016;374:344-53. 